Article

\title{
Lysis Profiles of Salmonella Phages on Salmonella Isolates from Various Sources and Efficiency of a Phage Cocktail against $S$. Enteritidis and $S$. Typhimurium
}

\author{
Kantiya Petsong ${ }^{1}$, Soottawat Benjakul ${ }^{1}$, Soraya Chaturongakul ${ }^{2}$, Andrea I. Moreno Switt ${ }^{3}$ (D) \\ and Kitiya Vongkamjan $1, *$ (D) \\ 1 Department of Food Technology, Prince of Songkla University, Hat Yai 90112, Thailand; \\ ann-kantiya@hotmail.com (K.P.); Soottawat.b@psu.ac.th (S.B.) \\ 2 Department of Microbiology, Mahidol University, Ratchathewi, Bangkok 10400, Thailand; \\ soraya.cha@mahidol.ac.th \\ 3 Escuela Medicina Veterinaria, Facultad de Ciencias de la Vida, Universidad Andres Bello, Republica 440, \\ 8370251 Santiago, Chile; andrea.moreno@unab.cl \\ * Correspondence: kitiya.v@psu.ac.th; Tel.: +66-74-286-337; Fax: +66-74-558-866
}

Received: 27 February 2019; Accepted: 1 April 2019; Published: 5 April 2019

\begin{abstract}
Salmonella enterica serovar Enteritidis and Salmonella enterica serovar Typhimurium are major foodborne pathogens of concern worldwide. Bacteriophage applications have gained more interest for biocontrol in foods. This study isolated 36 Salmonella phages from several animal farms in Thailand and tested them on 47 Salmonella strains from several sources, including farms, seafood processing plant and humans in Thailand and USA. Phages were classified into three major groups. The estimated phage genome size showed the range from $50 \pm 2$ to $200 \pm 2 \mathrm{~kb}$. An effective phage cocktail consisting of three phages was developed. Approximately $4 \log \mathrm{CFU} / \mathrm{mL}$ of $S$. Enteritidis and $S$. Typhimurium could be reduced. These phages revealed a burst size of up to 97.7 on $S$. Enteritidis and $173.7 \mathrm{PFU} /$ cell on $S$. Typhimurium. Our phage cocktail could decrease $S$. Enteritidis on chicken meat and sunflower sprouts by $0.66 \log \mathrm{CFU} / \mathrm{cm}^{2}$ and $1.27 \log \mathrm{CFU} / \mathrm{g}$, respectively. S. Typhimurium on chicken meat and sunflower sprouts were decreased by $1.73 \log \mathrm{CFU} / \mathrm{cm}^{2}$ and $1.17 \log \mathrm{CFU} / \mathrm{g}$, respectively. Overall, animal farms in Thailand provided high abundance and diversity of Salmonella phages with the lysis ability on Salmonella hosts from various environments and continents. A developed phage cocktail suggests a potential biocontrol against Salmonella in fresh foods.
\end{abstract}

Keywords: Salmonella phage; animal farm; phage host range; phage cocktail; Salmonella serovar; chicken meat; sunflower sprout

\section{Introduction}

Salmonella enterica serovars Enteritidis and Typhimurium have been reported as the most common causes of salmonellosis outbreaks related to food contamination [1]. The US Centers for Disease Control and Prevention (CDC) reported an estimation of 1 million domestically acquired salmonellosis cases with 19,000 hospitalizations and 380 deaths [2]. Animal farms are typically associated with the presence of diverse Salmonella serovars [3,4]. The environments around farms such as feedstuff, soil, water, and feces are common sources of Salmonella [4]. Distribution of Salmonella on farms leads to the likelihood of Salmonella contamination in various food of animal origin and produce. Salmonella serovars predominantly present in food can be differed, for example, serovars Enteritidis and Typhimurium are common in eggs [5], serovars Kentucky and Enteritidis are common in poultry [6], 
serovars Newport, Infantis and Javiana are common in fruits and vegetables [7]. The environments of food processing plant have been linked to occurrence of diverse Salmonella serovars. For example, serovars Weltevreden [8,9], Anatum, Enteritidis, Newport, and Typhimurium have been previously detected in wastewater from the plant [10]. Salmonella serovars predominant in human are also of crucial concern. These include Salmonella serovars Weltevreden, Enteritidis and Anatum which have been reported as the most common serovars isolated from human in Thailand [11]. The occurrence of Salmonella contaminated in poultry meat has been often reported [12]. Fresh produce such as sprout has also been reported as the high risk food that is commonly been contaminated by Salmonella [12,13]. Control of Salmonella in both food categories is thus crucial.

Bacteriophages (phages) are viruses of bacteria which are adapted to be very specific for infecting and killing bacterial hosts [14]. The habitat of phages is normally related to their hosts as predator and prey [15]. Phage application as a biocontrol agent against pathogens has been reported the outstanding properties over antibiotics (e.g., specificity to target hosts) [14] or chemical agents which are commonly used in meat products and may have some negative effects on human health [16]. Certain phages have been shown to have minimal effects on the change of quality and sensory properties of specific foods [17]. To improve the antibacterial efficiency and avoid phage-resistant bacteria from using phage-based biocontrol, phage cocktail is an alternative approach. Several studies have reported the success in using effective phage cocktails to control Salmonella serovars in various food products, including raw meat, fresh produce and ready-to-eat foods [18-20].

Phage abundance and diversity recovered from particular sources can provide a better understanding on the phage-host relationship. Phage lysis profiles obtained from testing phages against Salmonella strains from various sources are useful information for further development of phage-based control for targeting Salmonella serovars predominant in different sources. This study aimed to isolate Salmonella phages from animal farms (poultry, swine, goat and bovine) in Thailand and investigate phage lysis profiles on Salmonella strains from at least two geographical regions (Thailand and USA) isolated from different sources, including animal farms, food processing plants and humans that have a history of Salmonella infection. Phages presenting the highest lysis ability against the two most common Salmonella serovars (Enteritidis and Typhimurium) were further developed as a phage cocktail. One-step growth curves of all phages included in the cocktail were studied to determine phage biology including latent period and burst size. Our developed phage cocktail was evaluated the effectiveness in reducing $S$. Enteritidis and $S$. Typhimurium in vitro and in fresh foods (raw chicken meat and sunflower sprouts) during storage at $4{ }^{\circ} \mathrm{C}$.

\section{Materials and Methods}

\subsection{Sample Collection}

A total of 12 samples were collected from six animal farms, including poultry, swine, goat, and bovine farms in Songkhla province, Thailand between January 2014 and October 2016. Of six farms, three of which were commercial farms (poultry, swine and goat) and three others were free range farms (poultry and bovine). Approximately $500 \mathrm{~g}$ of each randomly selected sample (feces, feed, soil and drinking water) was collected using a sterile spatula and transferred to a sterile bag. Feces samples were collected from the floor inside the pens of the commercial farms where animals resided. For free range farms, feces samples were collected from random open areas where animals resided. Feed samples were taken from the storage containers freshly prepared for feeding animals. Soil samples were taken from the free range farms only and from random open areas where animals resided. Drinking water in farms was also collected. Each sample was kept in a cooler box containing ice packs and transferred to a laboratory. Collected samples were stored at $4{ }^{\circ} \mathrm{C}$ until analysis in the laboratory.

\subsection{Bacterial Strains Used in the Study}

Salmonella strains used in this study consisted of 47 Salmonella strains presenting 28 common serovars (Table 1). All Salmonella strains tested were the representative of predominant serovars isolated from 
various sources, including animal farms, food processing plants and humans in Thailand and USA. A total of 23 strains of Salmonella isolated from animal farms and human in the USA were obtained from Food Safety Laboratory, Cornell University (indicated with a prefix of "FSL"). Other 24 strains of Salmonella were previously isolated from animal farms, food processing plants and humans in Thailand. These were obtained from the Faculty of Microbiology, Mahidol University and the Faculty of Agro-Industry, Prince of Songkla University, Thailand (indicated with a prefix of "PSU-BS-"). Salmonella strains were kept in $15 \%$ glycerol at $-80^{\circ} \mathrm{C}$ as working stocks. For overnight culture, an isolated colony of Salmonella from Tryptone Soya Agar (TSA; Oxoid, Hampshire, UK) was transferred in $5 \mathrm{~mL}$ of Tryptone Soya Broth (TSB; Oxoid, Hampshire, UK) and incubated at $37^{\circ} \mathrm{C}$ for $16-18 \mathrm{~h}$.

Table 1. Salmonella strains used for phage isolation and determination of phage lysis profiles.

\begin{tabular}{|c|c|c|}
\hline Serovars & Isolates ID & Source (Country) \\
\hline Agona & $\begin{array}{l}\text { H2-016* } \\
\text { FSL S5-667 }\end{array}$ & $\begin{array}{c}\text { Pig slaughterhouse (Thailand) } \\
\text { Bovine (USA) }\end{array}$ \\
\hline \multirow[t]{2}{*}{ Anatum } & PSU-BS-104SL & $\begin{array}{l}\text { Seafood processing plant } \\
\text { (Thailand) }\end{array}$ \\
\hline & FSL A4-525* & Bovine (USA) \\
\hline Braenderup & FSL S5-373 & Human (USA) \\
\hline Cerro & FSL R8-242 & Bovine (USA) \\
\hline Corvolis & $\begin{array}{l}\text { PSU-BS-092SL } \\
\text { FSL R8-092 }\end{array}$ & $\begin{array}{c}\text { Animal farm (Thailand) } \\
\text { Human (USA) }\end{array}$ \\
\hline Dublin & $\begin{array}{l}\text { W1-016 } \\
\text { FSL S5-368 }\end{array}$ & $\begin{array}{l}\text { Dairy farm (Thailand) } \\
\text { Bovine (USA) }\end{array}$ \\
\hline \multirow{2}{*}{$\begin{array}{l}\text { Enteritidis } \\
\text { Give }\end{array}$} & FSL S5-371 & Human (USA) \\
\hline & $\begin{array}{l}\text { PSU-BS-181SL } \\
\text { H2-018* }\end{array}$ & $\begin{array}{l}\text { Animal farm (Thailand) } \\
\text { Dairy farm (Thailand) }\end{array}$ \\
\hline Heidelberg & FSL S5-455 & Human (USA) \\
\hline Infantis & FSL S5-506 & Human (USA) \\
\hline Javiana & FSL S5-406 & Human (USA) \\
\hline Kedougou & H2-061 & Pig slaughterhouse (Thailand) \\
\hline \multirow[t]{4}{*}{ Kentucky } & W1-010* & Dairy farm (Thailand) \\
\hline & PSU-BS-058SL & Chicken farm (Thailand) \\
\hline & PSU-BS-116SL & $\begin{array}{l}\text { Seafood processing plant } \\
\text { (Thailand) }\end{array}$ \\
\hline & FSL S5-431 & Bovine (USA) \\
\hline Krefeld & PSU-BS-111SL & $\begin{array}{l}\text { Seafood processing plant } \\
\text { (Thailand) }\end{array}$ \\
\hline \multirow[t]{3}{*}{ Mbandaka } & W1-015 & Dairy farm (Thailand) \\
\hline & PSU-BS-035SL & Chicken farm (Thailand) \\
\hline & FSL A4-793 & Bovine (USA) \\
\hline \multirow[t]{2}{*}{ Montevideo } & FSL S5-474 & Bovine (USA) \\
\hline & FSL S5-403 & Bovine (USA) \\
\hline Muennster & FSL S5-917 & Bovine (USA) \\
\hline Newport & FSL S5-548 & Bovine (USA) \\
\hline Oranienburg & FSL R8-376 & Human (USA) \\
\hline Ordonez & PSU-BS-181SL & $\begin{array}{l}\text { Seafood processing plant } \\
\text { (Thailand) }\end{array}$ \\
\hline Panama & FSL S5-454 & Human (USA) \\
\hline Rissen & H2-015 & Pig slaughterhouse (Thailand) \\
\hline Saintpaul & FSL S5-369 & Human (USA) \\
\hline \multirow[t]{3}{*}{ Stanley } & $\begin{array}{l}\text { PSU-BS-001SL } \\
\text { H2-002* }\end{array}$ & $\begin{array}{l}\text { Swine farm (Thailand) } \\
\text { Pig slaughterhouse (Thailand) }\end{array}$ \\
\hline & PSU-BS-041SALX & $\begin{array}{l}\text { Seafood processing plant } \\
\text { (Thailand) }\end{array}$ \\
\hline & FSL S5-464 & Human (USA) \\
\hline Tennessee & PSU-BS-183SL & $\begin{array}{l}\text { Seafood processing plant } \\
\text { (Thailand) }\end{array}$ \\
\hline \multirow[t]{2}{*}{ Typhimurium } & $\mathrm{H} 2-001$ * & Pig slaughterhouse (Thailand) \\
\hline & $\begin{array}{l}\text { PSU-BS-014SL } \\
\text { FSL S5-370 }\end{array}$ & $\begin{array}{c}\text { Chicken farm (Thailand) } \\
\text { Human (USA) }\end{array}$ \\
\hline \multirow[t]{2}{*}{ Virchow } & FSL H2-117* & Human (Thailand) \\
\hline & FSL S5-961 & Human (USA) \\
\hline \multirow[t]{3}{*}{ Weltevreden } & H2-031 & Pig slaughterhouse (Thailand) \\
\hline & PSU-BS-013SL & Chicken farm (Thailand) \\
\hline & FSL R8-798 & Human (USA) \\
\hline
\end{tabular}




\subsection{Isolation and Purification of Salmonella Phages}

Salmonella phages were isolated using enrichment isolation with a multi-strain Salmonella cocktail whose serovars are shown to be predominant in Thai animal farms (Agona H2-016, Anatum A4-525, Give H2-018, Kentucky W1-010, Stanley H2-002, Typhimurium H2-001, and Virchow H2-117) [11,21]. Briefly, $25 \mathrm{~g}$ of each sample was enriched with $225 \mathrm{~mL}$ of TSB and $2.5 \mathrm{~mL}$ of host mixture. After filtration of the mixture through $0.45 \mu \mathrm{m}$ and $0.22 \mu \mathrm{m}$ syringe filters, filtrate $(100 \mu \mathrm{L})$ was used to prepare the double layer by mixing with each host strain previously grown in TSB for $16-18 \mathrm{~h}$ at $37^{\circ} \mathrm{C}$. For each overlay, $300 \mu \mathrm{L}$ of the 1:10 dilution of the overnight host strain was mixed with $4 \mathrm{~mL}$ of $0.7 \%$ TSA, followed by incubation at $37^{\circ} \mathrm{C}$ for $18-24 \mathrm{~h}$. Plaques were observed on each host lawn. A distinct isolated plaque was selected and suspended in $300 \mu \mathrm{L}$ of Phosphate Buffered Saline (PBS, (pH 7.4), $137 \mathrm{mM} \mathrm{NaCl}, 2.7 \mathrm{mM} \mathrm{KCl}, 4.3 \mathrm{mM} \mathrm{Na} 2 \mathrm{HPO}_{4}, 1.4 \mathrm{mM} \mathrm{KH}_{2} \mathrm{PO}_{4}$ ) for purification. Serial dilutions were performed and appropriate dilution was subjected to three passages with a specific host that showed a positive result, using a double layer agar technique [4].

\subsection{Lysate Preparation and Titer Determination of Salmonella Phages}

An isolated plaque from the third purification passage was used to prepare 10-fold serial dilutions in PBS. Appropriate dilutions were used to prepare the overlay with a given host to yield semi-confluent lysis. Overlay was harvested with $10 \mathrm{~mL}$ of Salt-Magnesium buffer (SM buffer), followed by centrifugation at $3213 \times g$ for $15 \mathrm{~min}$ at $4{ }^{\circ} \mathrm{C}$. Supernatant was filtered through a $0.22 \mu \mathrm{m}$ syringe filter and phage lysates were kept at $4{ }^{\circ} \mathrm{C}$. Each phage lysate was serially diluted in PBS and $100 \mu \mathrm{L}$ of each dilution was mixed with $300 \mu \mathrm{L}$ of host, then the mixture was poured on bottom agar [22]. Phage titers were determined after incubation at $25^{\circ} \mathrm{C}$ for $16-18 \mathrm{~h}$ by counting plaques present on each plate of a given dilution [22].

\subsection{Determination of Lysis Profiles of Salmonella Phages}

Lysis profile for each phage was determined by a spot test on bacterial lawn of a given Salmonella strain in the collection included in this study. Briefly, $5 \mu \mathrm{L}$ of each phage lysate representing $10^{8} \mathrm{PFU} / \mathrm{mL}$ were spotted on the bacterial host lawn prepared as mentioned above but without filtrate. Phage lysis patterns were determined after $18-24 \mathrm{~h}$ of incubation at $25^{\circ} \mathrm{C}$. The experiment was performed in independent triplicates. Phage lysis patterns were analyzed by converting a positive lysis (zone of lysis on a spot) to a score of 1 and negative results were converted to a score of 0 . A heatmap representing lysis groups was generated by cluster analysis, following Vongkamjan et al. [22] with Ward's method of binary distance, using the R software program ( $R$ development Core Team 2012 [23].

\subsection{Genome Size Determination of Salmonella Phages}

Representative Salmonella phages from each sample source were selected for genome size determination. A total of 17 phage isolates were included for Pulsed-Field Gel Electrophoresis (PFGE) analysis. Agarose plugs were prepared by mixing equal volume $(55 \mu \mathrm{L})$ of a given phage lysate with high titer of approximately $10^{6}-10^{8} \mathrm{PFU} / \mathrm{mL}$ and $1.3 \%$ low melting point agarose. Plugs were kept at low temperature $\left(4^{\circ} \mathrm{C}\right)$ in order to solidify for $1 \mathrm{~h}$. Plugs were loaded into $1 \%$ agarose gel and electrophoresis was performed in 0.5X TBE buffer using CHEF-DR III system (Bio-Rad, Hercules, CA, USA). PFGE was performed for $20 \mathrm{~h}$ with $0.5-5 \mathrm{~s}$ of switch time. Two size markers were included; CHEF DNA size standard of 8-48 kb ladder and CHEF DNA size standard lambda $\lambda$ ladder $0.05-1 \mathrm{Mb}$ (both from Bio-Rad, Hercules, CA, USA) [4,22].

\subsection{Development of a Phage Cocktail Targeting Two Major Salmonella Serovars}

To develop a Salmonella phage cocktail against $S$. Enteritidis and $S$. Typhimurium, nine phages which showed the strong lysis ability on $S$. Enteritidis and S. Typhimurium (KP1, KP2, KP4, KP5, $\mathrm{KP9}, \mathrm{KP} 34, \mathrm{KP} 36, \mathrm{KP} 49$, and KP50) were ordered their lysis ability by a spotting test and efficiency of 
plating (EOP) using method modified from previous study [24]. In this study, $S$. Enteritidis FSL S5-371 and S. Typhimurium H2-001 were used as the target hosts. S. Anatum FSL A4-525 was used as the reference host of phages KP1, KP2, KP5 and KP9. S. Virchow H2-117 was used as the reference host of phages KP34 and KP36. S. Agona H2-016 was used as the reference host of phages KP49 and KP50. Three Salmonella phages which showed the highest lysis ability were selected to prepare a cocktail using a ratio of 1:1:1 for each phage.

\subsubsection{Spotting Assay}

Each Salmonella phage dilutions ranging in concentration from $10^{3}-10^{7} \mathrm{PFU} / \mathrm{mL}$ were spotted on bacterial lawn of $S$. Enteritidis or $S$. Typhimurium prepared as mentioned above. Immediately after spotting, the plates were incubated at $25^{\circ} \mathrm{C}$ for $16-18 \mathrm{~h}$. The clear zone or visible plaques formed by serial dilutions on the plate were determined as +++ , confluent lysis (clear spot); ++ , semi-confluent lysis (semi-clear); + , turbidity without plaque formation. The experiment was repeated three times for each phage.

\subsubsection{Efficiency of Plating (EOP) Assay}

Similar to a spotting assay, each Salmonella phage dilution ranging in concentrations from $10^{3}-10^{7} \mathrm{PFU} / \mathrm{mL}$ were spotted on bacterial lawn of $S$. Enteritidis or $S$. Typhimurium. EOP assay replicates for a particular phage were done in parallel on both reference and target hosts. The EOP was calculated by the ratio of the average PFU on a target host to the average PFU on a corresponding reference host. EOP values were presented in 3 levels; high production (EOP $\geq 0.5$ ), medium production $(0.01 \leq \mathrm{EOP}<0.5)$ and low production $(0.0001<\mathrm{EOP}<0.01)$.

\subsection{One-Step Growth Curve}

A one-step growth curve for three phages included in the phage cocktail were investigated following a protocol of Bao et al. [25] with modifications. The bacterial hosts $S$. Enteritidis and $S$. Typhimurium grown overnight $\left(10^{7} \mathrm{CFU} / \mathrm{mL}\right)$ in TSB as mentioned above were mixed with $10^{8} \mathrm{PFU} / \mathrm{mL}$ and $10^{9} \mathrm{PFU} / \mathrm{mL}$ of phage to a final volume of $30 \mathrm{~mL}$ to represent the multiplicity of infection (MOI) of 10 and 100, respectively. The co-culture was incubated at $37^{\circ} \mathrm{C}(220 \mathrm{rpm})$ for an initial attachment for $20 \mathrm{~min}$, followed by centrifugation of the sample at $6000 \times \mathrm{g}$ for $10 \mathrm{~min}$ at $4{ }^{\circ} \mathrm{C}$ to remove the excess phage as the supernatant. Cell pellets were re-suspended with the same volume $(30 \mathrm{~mL})$ as pre-centrifugation with TSB and resumed to incubation for additional $60 \mathrm{~min}$. Lysate $(1 \mathrm{~mL})$ was taken every $5 \mathrm{~min}$ for the standard plaque count assay (in triplicates) to determine the number of phages obtained from each period. Latent period was defined as the time interval between the adsorption (not including 20 min of pre-incubation) and the beginning of the first burst, as indicated by the initial rise in the phage titer. Burst size was calculated as the ratio of the final count of liberated phage particles to the initial count of infected bacterial cells during the latent period.

\subsection{Efficiency of Phage Cocktail to Reduce S. Enteritidis and S. Typhimurium In Vitro and Evaluation of Phage-Resistance in Salmonella after Treated with Phage Cocktail}

An overnight culture of $S$. Enteritidis and $S$. Typhimurium prepared as mentioned above $(10 \mathrm{~mL})$ was separately centrifuged at $6000 \times g$ for $10 \mathrm{~min}$ at $4{ }^{\circ} \mathrm{C}$. To wash cell pellets, $5 \mathrm{~mL}$ of PBS were added and centrifuged at the same conditions three times. Washed Salmonella pellets were suspended in TSB and diluted to approximately $10^{5} \mathrm{CFU} / \mathrm{mL}$. Phage cocktail stock was diluted with TSB to achieve phage concentration at $10^{7} \mathrm{PFU} / \mathrm{mL}$. Each Salmonella strain suspension and phage cocktail preparation were mixed at a ratio of $1: 1$ by volume and incubated at $37^{\circ} \mathrm{C}$ in a shaking incubator (ThermoStable ${ }^{\mathrm{TM}}$ IS-30 model, DAIHAN Scientific, Gangwon-do, Korea) at $220 \mathrm{rpm}$ for $12 \mathrm{~h}$. Controls included in the study were only $S$. Enteritidis and $S$. Typhimurium cultured in TSB. The cell numbers of $S$. Enteritidis and $S$. Typhimurium from the treatments and controls at each temperature tested were enumerated 
every $4 \mathrm{~h}$ interval by a spread plate on TSA. After $12 \mathrm{~h}$ of experiment, samples were collected for the analyses of phage resistance.

The changes in resistance phenotype of $S$. Enteritidis and $S$. Typhimurium after treated with a phage cocktail were evaluated by a spotting test. Five colonies of $S$. Enteritidis and $S$. Typhimurium from controls and treatments of phage cocktail recovered from TSA after $12 \mathrm{~h}$ of experiment above were re-cultured in TSB, followed by incubation at $37^{\circ} \mathrm{C}$ for $16-18 \mathrm{~h}$. Each culture was used to prepare an overlay for a spotting test. Serial dilutions $\left(10^{3}-10^{7} \mathrm{PFU} / \mathrm{mL}\right)$ of phage cocktail and each individual phage mixed in a cocktail were spotted on each bacterial lawn. Phage lysis patterns were determined after $18-24 \mathrm{~h}$ of incubation at $25^{\circ} \mathrm{C}$.

\subsection{Efficiency of Phage Cocktail to Reduce S. Enteritidis and S. Typhimurium in Foods}

Chicken meat and sunflower sprouts were selected as representative foods which commonly have Salmonella contamination. Samples were purchased from the supermarkets in Hat Yai, Thailand. To eliminate Salmonella that may be present, the samples were soaked in $50 \mathrm{ppm}$ free chlorine concentration solution for $5 \mathrm{~min}$ [26]. Subsequently, the samples were soaked and washed in sterile distilled water for $5 \mathrm{~min}$ for 3 times. Chicken breast was aseptically cut into pieces of approximately $5 \times 5 \mathrm{~cm}^{2}$ and sunflower sprout was aseptically weight approximately $5 \mathrm{~g}$. Overnight culture of $S$. Enteritidis and S. Typhimurium was prepared. Cell pellets were suspended with PBS and diluted to obtain the final concentration of $10^{5} \mathrm{CFU} / \mathrm{mL}$. One milliliter of each Salmonella strain was evenly spiked to the surface of each piece of chicken breast and sunflower sprout in a sterile Whirl-Pak bag to achieve the inoculation level of approximately $10^{5} \mathrm{CFU} /$ piece or $10^{5} \mathrm{CFU} / 5 \mathrm{~g}$. Samples were left on clean bench for $10 \mathrm{~min}$ to allow the cells to adapt to the conditions on food samples tested. A phage cocktail preparation $\left(1 \mathrm{~mL}\right.$ containing $10^{7} \mathrm{PFU} / \mathrm{mL}$ ) was evenly spiked to each piece of chicken and sunflower sprout in a sterile Whirl-Pak bag. PBS buffer $(1 \mathrm{~mL})$ was added to sample inoculated with Salmonella as control. Treatments and control were stored at $4{ }^{\circ} \mathrm{C}$. Number of Salmonella cells was enumerated on day 0,1 , 2, 3, and 4 on Xylose-Lysine-Desoxycholate agar (XLD; Oxoid, Hampshire, UK).

\subsection{Statistical Analysis}

Differences of the bacterial counts between control and treatment by a phage cocktail in this study were analyzed by Student's $t$-test for both in vitro and in food models. The Analysis of variance (ANOVA) was used to compare differences between the storage period for a given strain. Comparison of means was carried out by Duncan's multiple range tests. Significance was declared at $p<0.05$ using the statistical Package for Social Science (SPSS 10.0 for windows, SPSS Inc., Chicago, IL, USA).

\section{Results}

\subsection{Recovery of Salmonella Phages from Various Animal Farms in Thailand}

Of 12 samples collected from three sampling visits to various animal farm environments in Songkhla province, Thailand, 36 Salmonella phages were obtained (Table 2). Three samples from sampling visit 1 from commercial farms represented two phages. Vast numbers of phages (34 phages) were obtained from the other 9 samples from two samplings at free range farms. Genome sizes of representative phages from different animal farms and different sources were estimated by PFGE analysis. Of the 17 representative phages, isolated phages from feces, feed, soil and drinking water from poultry farms, they showed an estimated genome size in the range of $50 \pm 2 \mathrm{~kb}$ to $105 \pm 2 \mathrm{~kb}$ (Table 3). An estimated genome size of $200 \pm 2 \mathrm{~kb}$ was observed in phages isolated from goat feces. Whereas, phages isolated from bovine feces showed an estimated genome size of $50 \pm 2 \mathrm{~kb}$ and $60 \pm 2 \mathrm{~kb}$. Overall, phages isolated in this study showed an estimated genome size in the range of $50 \pm 2 \mathrm{~kb}$ to $200 \pm 2 \mathrm{~kb}$. 
Table 2. Recovery of Salmonella phages from various animal farms in Thailand.

\begin{tabular}{cc}
\hline Animal Farms (Sampling Date [mo/yr]) & Number of Sample (Number of Phages) \\
\hline Sampling 1 (04/2014) & $1(1)$ \\
Poultry farm; commercial & $1(0)$ \\
Swine farm; commercial & $1(1)$ \\
Goat farm; commercial & $1(3)$ \\
Sampling 2 (08/2015) & $4(15)$ \\
Bovine farm; free range & $4(16)$ \\
Poultry farm; free range & $12(36)$ \\
Sampling 3 (10/2016) & \\
Poultry farm; free range & Total
\end{tabular}

Table 3. Estimated genome size of representative Salmonella phages from various animal farms in this study.

\begin{tabular}{llc}
\hline \multicolumn{1}{c}{ Salmonella Phage ID } & \multicolumn{1}{c}{ Source } & Estimated Genome Size (kb) \\
\hline KP3 & Goat feces & $200 \pm 2$ \\
KP4 & Soil (poultry farm 2) & $105 \pm 2$ \\
KP5 & Poultry feces (poultry farm 3) & $60 \pm 2$ \\
KP6 & Poultry feed (poultry farm 2) & $62 \pm 2$ \\
KP7 & Soil (poultry farm 2) & $60 \pm 2$ \\
KP10 & Poultry feed (poultry farm 2) & $60 \pm 2$ \\
KP11 & Soil (poultry farm 2) & $60 \pm 2$ \\
KP34 & Poultry feces (poultry farm 1) & $60 \pm 2$ \\
KP38 & Bovine feces & $50 \pm 2$ \\
KP39 & Bovine feces & $97 \pm 2$ \\
KP41 & Drinking water (poultry farm 3) & $60 \pm 2$ \\
KP43 & Poultry feces (poultry farm 3) & $60 \pm 2$ \\
KP49 & Soil (poultry farm 3) & $103 \pm 2$ \\
KP50 & Poultry feces (poultry farm 3) & $50 \pm 2$ \\
KP53 & Poultry feces (poultry farm 3) & $50 \pm 2$ \\
KP54 & Soil (poultry farm 3) & $60 \pm 2$ \\
KP55 & Poultry feed (poultry farm 3) & \\
\hline
\end{tabular}

3.2. Lysis Profiles of Salmonella Phages from Animal Farms on Salmonella Strains from Various Sources in Thailand and USA

All 36 Salmonella phages obtained in this study were tested on 47 Salmonella strains representing 28 serovars. These phages were classified into three groups based on the host range, including (A) broad, (B) narrow and ( $\mathrm{A}^{*}$ ) special broad host range (Figure 1). In group A, 14 phages showed strong lysis ability with Salmonella strains from Thailand but lower weaker lysis ability with Salmonella strains from USA However, several phages showed ability to lyse Salmonella strains from both continents and different sources. In group B, 21 phages showed the ability to lyse Salmonella strains mostly isolated from Thailand, especially Salmonella isolated from animal farms. One unique phage (KP34) isolated from a commercial poultry farm was classified into the special broad host range group. This phage showed the broadest host range among isolated phages with the ability to lyse over $60 \%$ of Salmonella strains from Thailand and $48 \%$ of Salmonella strains from USA Overall, phages isolated in this study presented different spectrum to lyse host strains from both continents and different sources. 


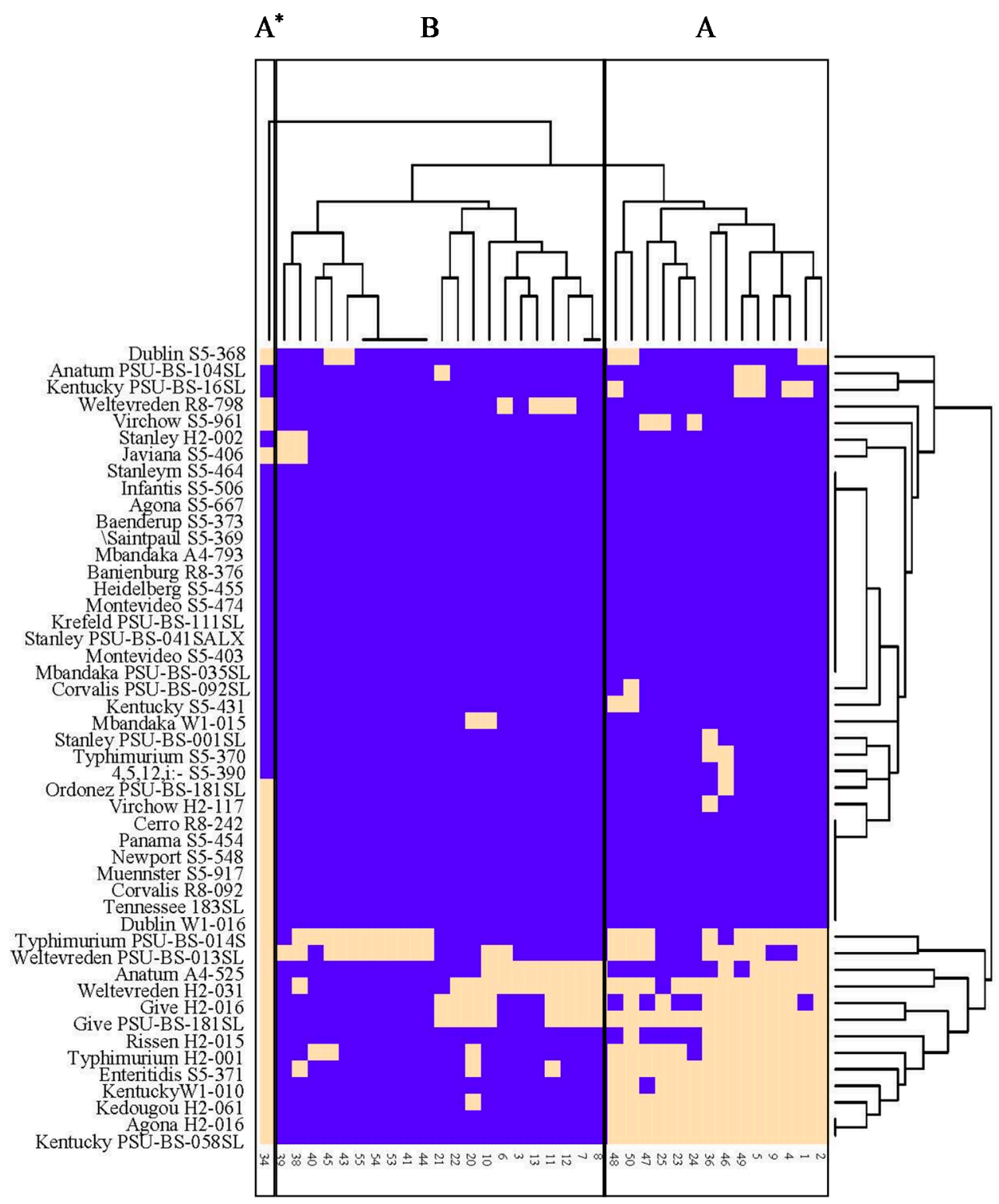

Figure 1. Heatmap representation of lysis profiles of 36 Salmonella phages tested (vertical axis) on 47 Salmonella host strains (horizontal axis) from Thailand and USA Phages were classified into three groups, including (A) broad, (B) narrow and ( $\left.\mathbf{A}^{*}\right)$ special broad host range. Beige areas indicate lysis and darker areas indicate no lysis.

\subsection{Phage Susceptibility of Different Salmonella Serovars from Various Sources}

All 36 Salmonella phages obtained in this study were tested on 47 Salmonella strains of different major serovars previously isolated from the environments related to animal farms, animal slaughterhouse and food processing plant and from humans. High susceptibility to phage lysis was observed among Salmonella strains mostly isolated from animal farms and slaughterhouse in Thailand (Table 4), including serovars Agona, Give, Kedougou, Kentucky, Typhimurium and Weltevreden. Two additional strains showing high susceptibility to phage lysis included serovars Anatum and Enteritidis. Other five serovars, including Kentucky, Rissen, Dublin, Virchow and Weltevreden from diverse sources from both Thailand and USA presented medium susceptibility to phage lysis. Several serovars showed low susceptibility to phage lysis. However, among serovars classified in this group, most Salmonella strains were isolated from USA These included serovars Agona, Braenderup, Heidelberg, 
Infantis, Javiana, Kentucky, Mbandaka, Montevideo, Muenster, Newport, Oranienburg, Panama, Saintpaul, Stanley and Typhimurium.

Table 4. Phage susceptibility of different Salmonella serovars recovered from various sources.

\begin{tabular}{|c|c|c|c|}
\hline \multirow{2}{*}{ Serovars } & \multirow{2}{*}{ Source } & \multicolumn{2}{|c|}{$\%$ Susceptibility (Level) ${ }^{a}$} \\
\hline & & Thailand & USA \\
\hline Agona & Pig slaughterhouse & $41.7(\mathrm{H})$ & - \\
\hline Anatum & Bovine & - & $41.7(\mathrm{H})$ \\
\hline Enteritidis & Human & - & $50.0(\mathrm{H})$ \\
\hline \multirow[t]{2}{*}{ Give } & Animal farm & $63.9(\mathrm{H})$ & - \\
\hline & Dairy farm & $50.0(\mathrm{H})$ & - \\
\hline Kedougou & Pig slaughterhouse & $44.4(\mathrm{H})$ & - \\
\hline \multirow[t]{2}{*}{ Kentucky } & Dairy farm & $38.9(\mathrm{H})$ & - \\
\hline & Chicken farm & $41.7(\mathrm{H})$ & - \\
\hline \multirow[t]{2}{*}{ Typhimurium } & Pig slaughterhouse & $47.2(\mathrm{H})$ & - \\
\hline & Chicken farm & $55.6(\mathrm{H})$ & - \\
\hline \multirow[t]{2}{*}{ Weltevreden } & Pig slaughterhouse & $69.4(\mathrm{H})$ & - \\
\hline & Chicken farm & $58.3(\mathrm{H})$ & - \\
\hline Dublin & Bovine & - & $19.4(\mathrm{M})$ \\
\hline Kentucky & Seafood processing plant & $13.9(\mathrm{M})$ & - \\
\hline Rissen & Pig slaughterhouse & $27.8(\mathrm{M})$ & - \\
\hline Virchow & Human & - & $11.1(\mathrm{M})$ \\
\hline Weltevreden & Human & - & $13.9(\mathrm{M})$ \\
\hline Agona & Bovine & - & No lysis \\
\hline Anatum & Seafood processing plant & $8.3(\mathrm{~L})$ & - \\
\hline Braenderup & Human & - & No lysis \\
\hline Cerro & Bovine & $2.8(\mathrm{~L})$ & - \\
\hline \multirow[t]{2}{*}{ Corvalis } & Animal farm & $2.8(\mathrm{~L})$ & - \\
\hline & Human & $2.8(\mathrm{~L})$ & - \\
\hline Dublin & Dairy farm & $2.8(\mathrm{~L})$ & - \\
\hline Heidelberg & Human & - & No lysis \\
\hline Infantis & Human & - & No lysis \\
\hline Javiana & Human & - & $8.3(\mathrm{~L})$ \\
\hline Kentucky & Bovine & - & $5.6(\mathrm{~L})$ \\
\hline Krefeld & Seafood processing plant & No lysis & - \\
\hline \multirow[t]{3}{*}{ Mbandaka } & Dairy farm & $5.6(\mathrm{~L})$ & - \\
\hline & Chicken farm & No lysis & - \\
\hline & Bovine & - & No lysis \\
\hline \multirow[t]{2}{*}{ Montevideo } & Bovine & - & No lysis \\
\hline & Bovine & - & No lysis \\
\hline Muennster & Bovine & - & $2.8(\mathrm{~L})$ \\
\hline Newport & Bovine & - & $2.8(\mathrm{~L})$ \\
\hline Oranienburg & Human & - & No lysis \\
\hline Ordonez & Seafood processing plant & $5.6(\mathrm{~L})$ & - \\
\hline Panama & Human & - & $2.8(\mathrm{~L})$ \\
\hline Saintpaul & Human & - & No lysis \\
\hline \multirow[t]{4}{*}{ Stanley } & Swine farm & $2.8(\mathrm{~L})$ & - \\
\hline & Pig slaughterhouse & $5.6(\mathrm{~L})$ & - \\
\hline & Seafood processing plant & No lysis & - \\
\hline & Human & - & No lysis \\
\hline Tennessee & Seafood processing plant & $2.8(\mathrm{~L})$ & - \\
\hline Typhimurium & Human & - & $5.6(\mathrm{~L})$ \\
\hline Virchow & Human & $5.6(\mathrm{~L})$ & - \\
\hline
\end{tabular}

a Phage susceptibility level defined by $\%$ of total phages that could lyse each host strain $(n=36):<10 \%$ (Low; L); $11-30 \%$ (Medium; M); $>31 \%$ (High; H). If no strain tested, ' - ' is shown in table. 


\subsection{Development of a Phage Cocktail}

Of 36 isolated Salmonella phages evaluated for a lysis profile, 9 phages showed strong lysis ability on $S$. Enteritidis and $S$. Typhimurium. Based on the highest EOP, three phages (KP4, KP5 and KP50) were selected for the development of a phage cocktail (Table 5). Each phage composed in a phage cocktail preparation showed the latent period on $S$. Enteritidis as 5, 15 and $40 \mathrm{~min}$ at MOI 100, and 10, 15 and $10 \mathrm{~min}$ at MOI 10 for phages KP4, KP5 and KP50, respectively (Table 6, Figure 2). On $S$. Typhimurium, these phages showed the latent period of 10,10 and $15 \mathrm{~min}$ at MOI 100, and 15, 15 and 10 min at MOI 10 for phages KP4, KP5 and KP50, respectively. Phages KP4, KP5 and KP50 included in a phage cocktail preparation showed large burst sizes as 25.1, 30.1 and $97.7 \mathrm{PFU} /$ cell, respectively on S. Enteritidis at MOI 100. At MOI 10, the burst sizes of phages KP4, KP5 and KP50 on $S$. Enteritidis were observed as 16.6, 6.6 and 37.1 PFU/cell, respectively. On the S. Typhimurium host, the burst size of phages KP4, KP5 and KP50 was observed as 70.8, 173.7 and 112.2 PFU/cell, respectively at MOI 100, and 19.1,19.1 and 28.8 PFU/cell, respectively at MOI 10.

Table 5. Lysis ability and efficiency of plating (EOP) of Salmonella phages on S. Enteritidis and S. Typhimurium.

\begin{tabular}{|c|c|c|c|c|c|c|c|c|}
\hline \multirow{3}{*}{$\begin{array}{c}\text { Salmonella } \\
\text { Phage }\end{array}$} & \multirow{3}{*}{$\begin{array}{l}\text { Reference } \\
\text { Salmonella } \\
\text { Serovar }\end{array}$} & \multirow{3}{*}{$\begin{array}{c}\text { Target } \\
\text { Salmonella } \\
\text { Serovar }\end{array}$} & \multicolumn{5}{|c|}{ Lysis Ability $^{a}$} & \multirow{3}{*}{$\begin{array}{c}\text { Level of } \\
\text { EOP }^{b}\end{array}$} \\
\hline & & & \multicolumn{5}{|c|}{ Phage Titer (PFU/mL) } & \\
\hline & & & $10^{7}$ & $10^{6}$ & $10^{5}$ & $10^{4}$ & $10^{3}$ & \\
\hline \multirow{2}{*}{ KP1 } & Anatum & Enteritidis & +++ & ++ & - & - & - & Medium \\
\hline & $(\mathrm{A} 4-525)$ & Typhimurium & ++ & - & - & - & - & Medium \\
\hline \multirow{2}{*}{ KP2 } & Anatum & Enteritidis & +++ & +++ & ++ & - & - & Medium \\
\hline & (A4-525) & Typhimurium & +++ & ++ & - & - & - & Low \\
\hline \multirow{2}{*}{ KP4 } & Anatum & Enteritidis & +++ & +++ & +++ & + & - & Medium \\
\hline & (A4-525) & Typhimurium & +++ & +++ & +++ & + & - & Medium \\
\hline \multirow{2}{*}{ KP5 } & Anatum & Enteritidis & +++ & +++ & +++ & + & - & Medium \\
\hline & (A4-525) & Typhimurium & +++ & +++ & ++ & - & - & Medium \\
\hline \multirow{2}{*}{ KP9 } & Anatum & Enteritidis & +++ & +++ & +++ & ++ & - & High \\
\hline & $(\mathrm{A} 4-525)$ & Typhimurium & +++ & + & - & - & - & Low \\
\hline \multirow{2}{*}{ KP34 } & Virchow & Enteritidis & +++ & +++ & ++ & - & - & Medium \\
\hline & (H2-117) & Typhimurium & ++ & - & - & - & - & Low \\
\hline \multirow{2}{*}{ KP36 } & Virchow & Enteritidis & +++ & +++ & +++ & ++ & - & Medium \\
\hline & (H2-117) & Typhimurium & ++ & - & - & - & - & Low \\
\hline \multirow{2}{*}{ КР49 } & Agona & Enteritidis & ++ & - & - & - & - & Low \\
\hline & (H2-016) & Typhimurium & ++ & - & - & - & - & Low \\
\hline \multirow{2}{*}{ KP50 } & Agona & Enteritidis & +++ & +++ & +++ & +++ & + & High \\
\hline & (H2-016) & Typhimurium & +++ & +++ & +++ & + & - & Medium \\
\hline
\end{tabular}

${ }^{a}$ Clear zone or visible plaques were observed as +++ , confluent lysis (clear spot); ++ , semi-confluent lysis (semi-clear); + , turbidity without plaque formation. ${ }^{b}$ EOP values were presented in 3 levels: high production (EOP $\geq 0.5)$, medium production. $(0.01 \leq \mathrm{EOP}<0.5)$ and low production $(0.0001<\mathrm{EOP}<0.01)$.

Table 6. Latent period and burst size of Salmonella phages included in a phage cocktail preparation.

\begin{tabular}{ccccccccc}
\hline \multirow{2}{*}{$\begin{array}{c}\text { Salmonella } \\
\text { Phage ID }\end{array}$} & \multicolumn{3}{c}{ Latent Period (min) } & \multicolumn{4}{c}{ Burst Size (PFU/Cell) } \\
\cline { 2 - 9 } & \multicolumn{2}{c}{ S. Enteritidis } & S. Typhimurium & S. Enteritidis & \multicolumn{2}{c}{ S. Typhimurium } \\
\cline { 2 - 9 } & MOI 100 & MOI 10 & MOI 100 & MOI 10 & MOI 100 & MOI 10 & MOI 100 & MOI 10 \\
\hline KP4 & 5 & 10 & 15 & 10 & 25.1 & 16.6 & 70.8 & 19.1 \\
KP5 & 15 & 15 & 10 & 15 & 30.1 & 6.6 & 173.7 & 19.1 \\
KP50 & 40 & 10 & 15 & 10 & 97.7 & 37.2 & 112.2 & 28.8 \\
\hline
\end{tabular}


A-1

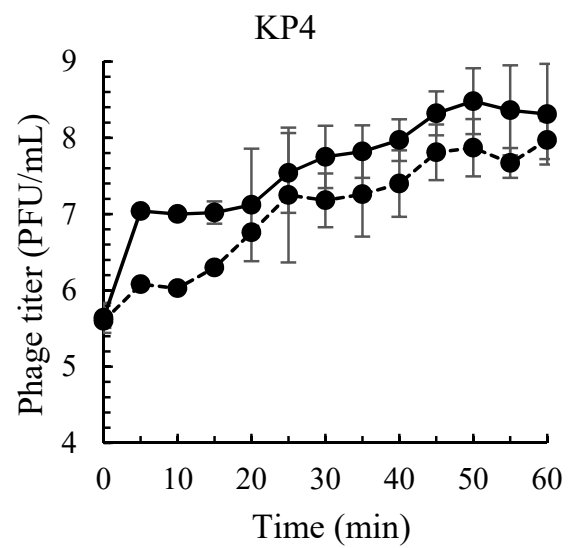

A-2

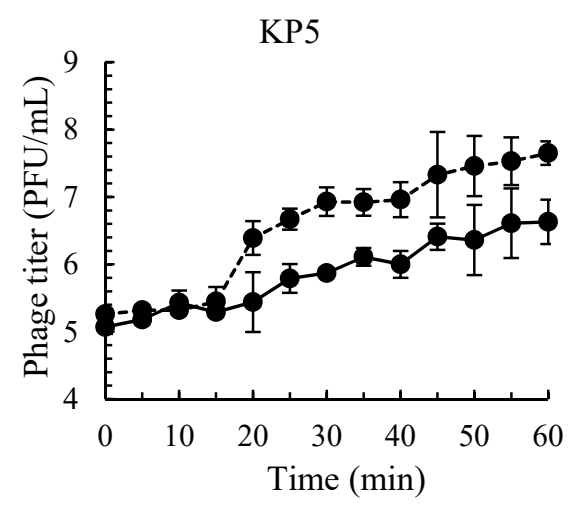

A-3

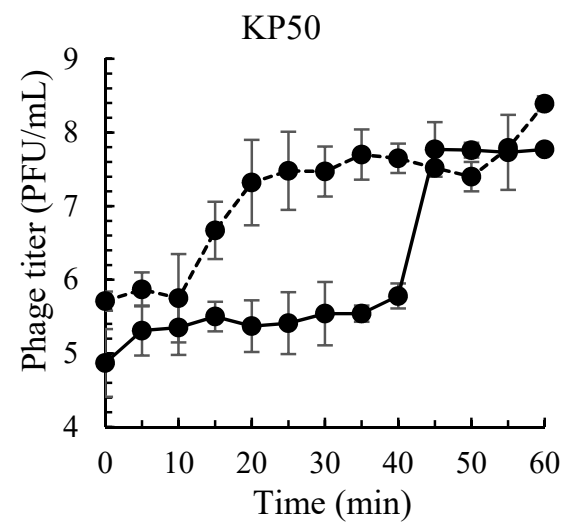

B-1

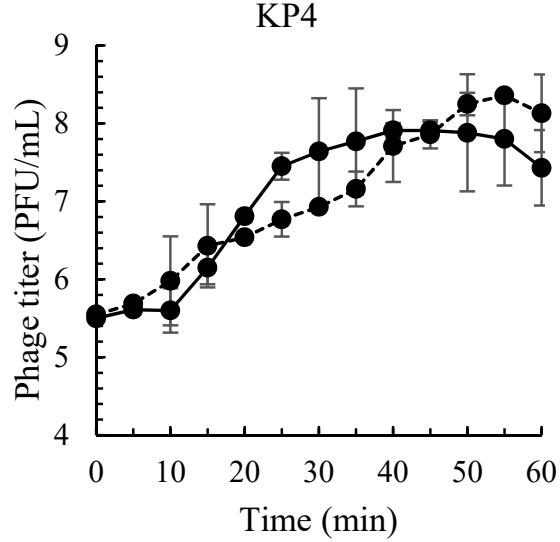

B-2

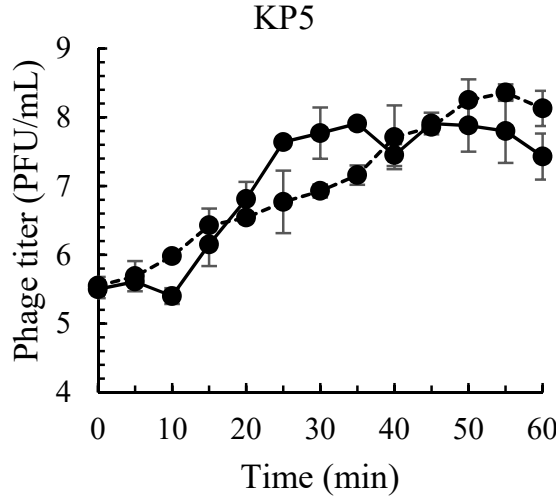

B-3

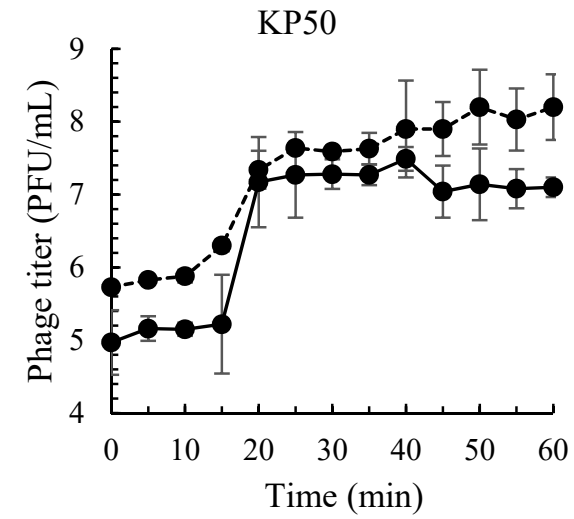

Figure 2. One-step growth curve of phage KP4, KP5 and KP50 on $S$. Enteritidis (A-1, A-2 and A-3) and S. Typhimurium (B-1, B-2 and B-3). MOI 100 presented by $\longrightarrow-$ and MOI 10 presented by ----Bars represent the mean standard deviation $(n=3)$.

3.5. Efficiency of Salmonella Phage Cocktail in Reducing S. Enteritidis and S. Typhimurium In Vitro and Different Fresh Foods, and Evidence of Phage-Resistant Development in Salmonella

In vitro study showed that a phage cocktail could decrease the numbers of $S$. Enteritidis and S. Typhimurium as indicated by the highest reduction of both serovars of more than $4 \log \mathrm{CFU} / \mathrm{mL}$ after $4 \mathrm{~h}$ of a phage cocktail treatment at MOI 100 (Figure 3). During the $8 \mathrm{~h}$ treatment, an overall reduction of more than $3 \log \mathrm{CFU} / \mathrm{mL}$ was observed for both strains tested. In chicken meat artificially contaminated with Salmonella, a high reduction of $S$. Enteritidis was observed in phage-treated chicken meat on day $2\left(0.53 \log \mathrm{CFU} / \mathrm{cm}^{2}\right)$ and day $4\left(0.66 \log \mathrm{CFU} / \mathrm{cm}^{2}\right)$ (Figure 4$)$. For $S$. Typhimurium, a 
high reduction was observed in phage-treated chicken meat on day $2\left(1.39 \log \mathrm{CFU} / \mathrm{cm}^{2}\right)$ and day 3 $\left(1.73 \log \mathrm{CFU} / \mathrm{cm}^{2}\right)$.

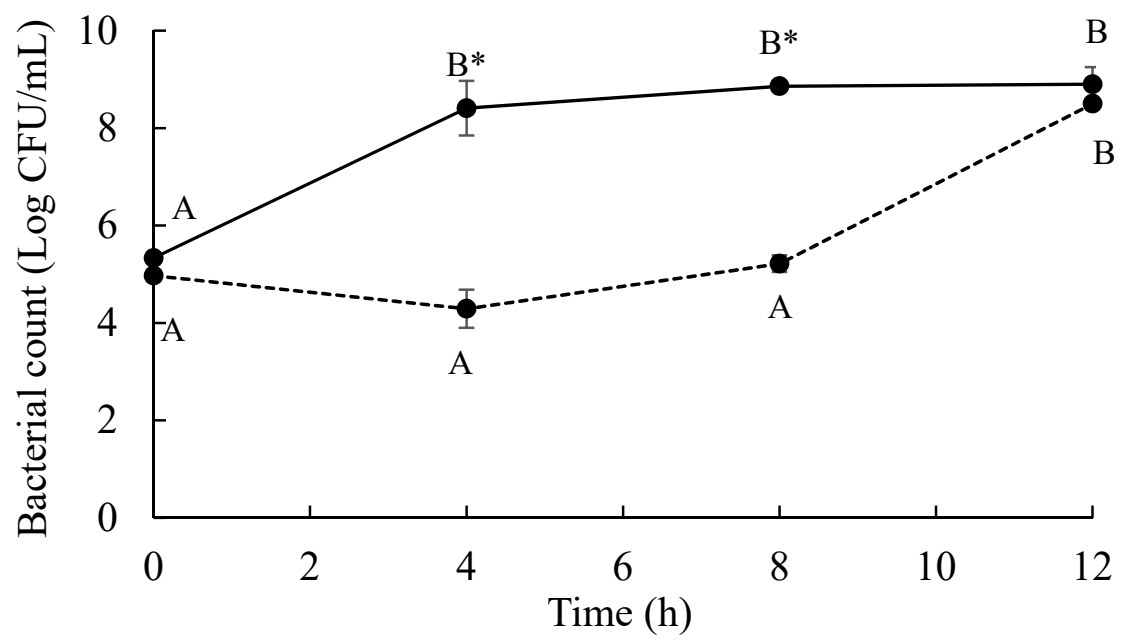

(a)

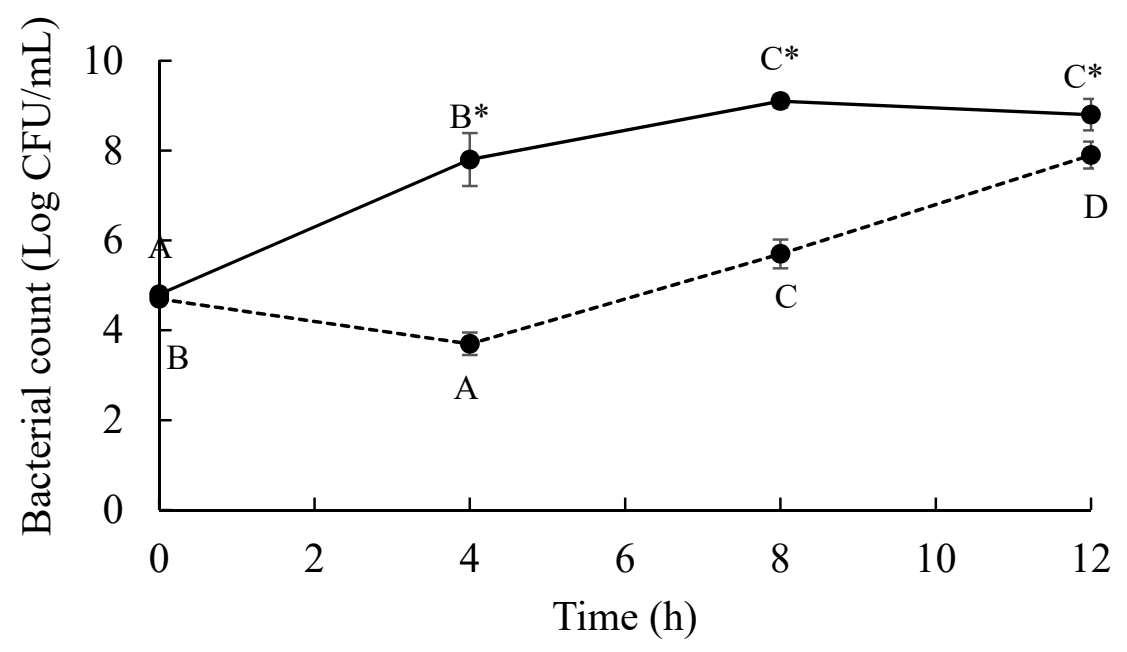

(b)

Figure 3. Survival of (a) S. Enteritidis and (b) S. Typhimurium treated with a phage cocktail at $37^{\circ} \mathrm{C}$ for $12 \mathrm{~h}$. Control (non-phage cocktail treated) presented by $\longrightarrow-$ and treatment of a phage cocktail presented by ----. Bars represent the mean standard deviation $(n=3)$. The sign $\left(^{*}\right)$ on the lines indicates significant differences $(p<0.05)$ of bacterial count between control and treatment during storage time for a given Salmonella strain. Different uppercase letters on the lines indicate significant differences $(p<0.05)$ of bacterial count among days of storage for a given Salmonella strain.

A phage cocktail treatment showed a high reduction of $S$. Enteritidis in sunflower sprouts on day 1 (1.27 $\log$ CFU/g) and day 4 (0.91 log CFU/g). For $S$. Typhimurium, a high reduction was observed in phage-treated sunflower sprout on day $2(1.17 \log \mathrm{CFU} / \mathrm{g})$ and day $4(1.17 \mathrm{log} \mathrm{CFU} / \mathrm{g})$. Overall, during 4 days of storage at $4{ }^{\circ} \mathrm{C}$, the numbers of $S$. Enteritidis and $S$. Typhimurium were decreased by 0.66 and $1.73 \log \mathrm{CFU} / \mathrm{cm}^{2}$ in chicken meat and 1.27 and $1.17 \mathrm{log} \mathrm{CFU} / \mathrm{g}$ in sunflower sprouts, respectively. Results indicate a potential use of this phage cocktail in chicken meat and sunflower sprouts during a storage condition at $4{ }^{\circ} \mathrm{C}$ for 4 days. 


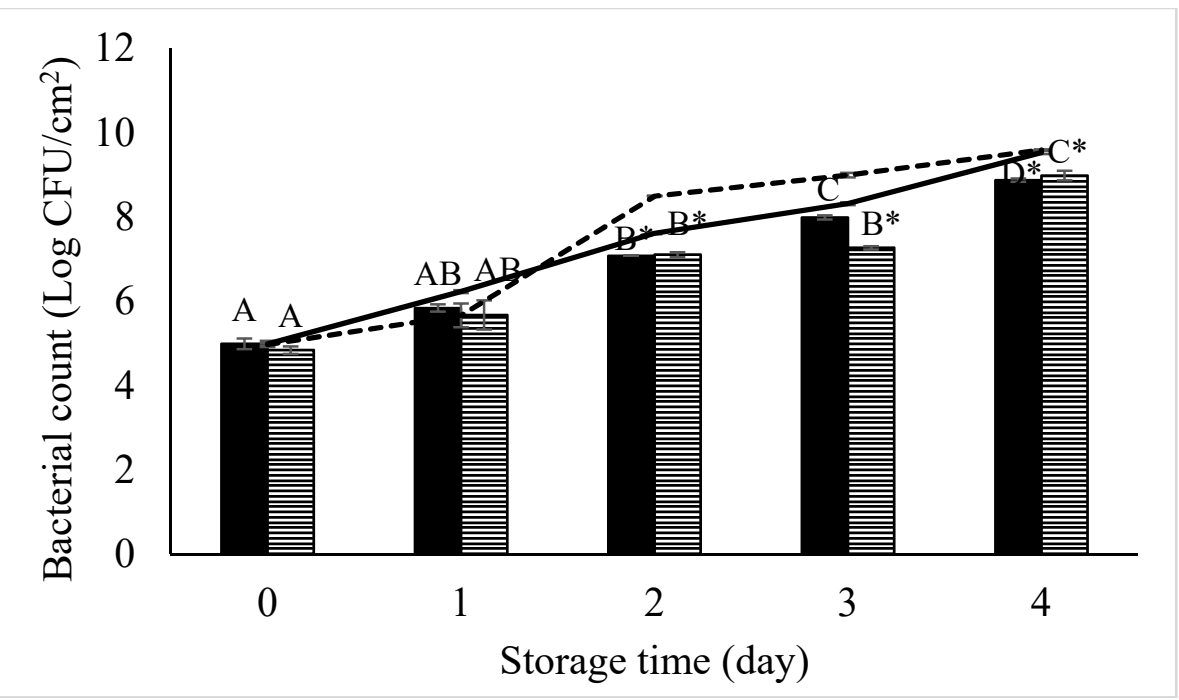

(a)

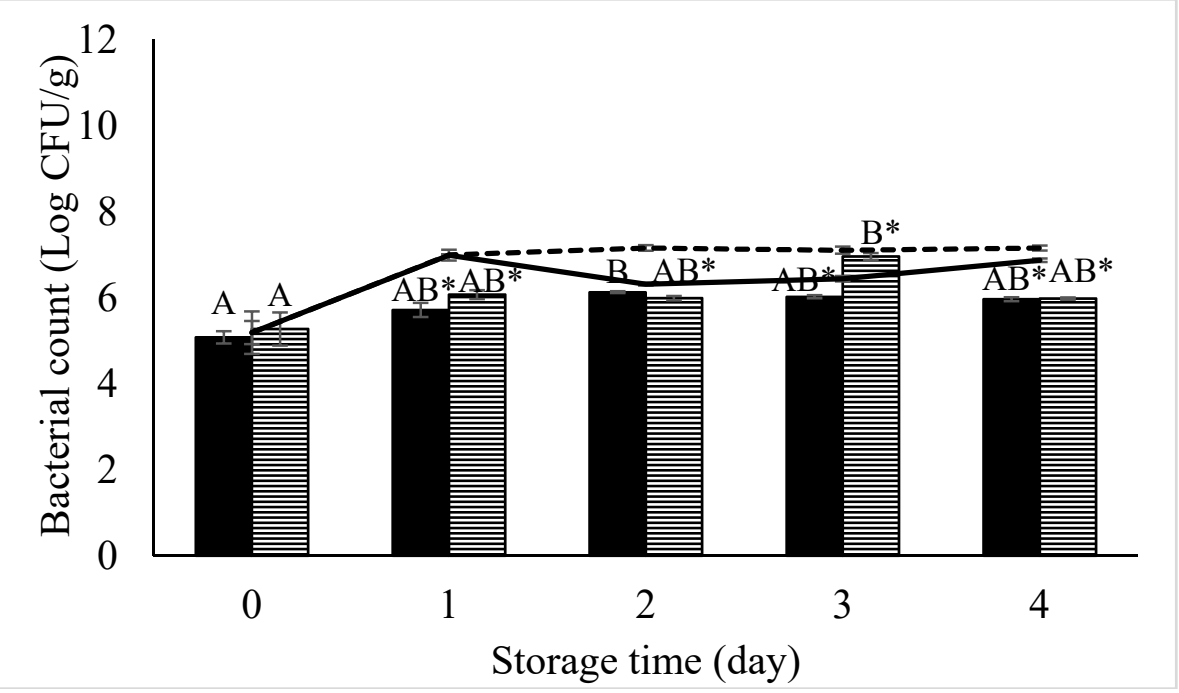

(b)

Figure 4. Recovery of $S$. Enteritidis ( $\square$ ) and $S$. Typhimurium (⿴囗⿱一一) ) artificially contaminated in (a) chicken meat and (b) sunflower sprouts treated with a phage cocktail and stored at $4{ }^{\circ} \mathrm{C}$ for 4 days. Control (non-phage cocktail treated) of $S$. Enteritidis and S. Typhimurium inoculated on both samples presented by solid line and dashed line, respectively. Bars represent the mean standard deviation $(n$ $=3)$. The sign $\left(^{*}\right)$ on the bars indicates significant differences $(p<0.05)$ of bacterial count between control and treatment during storage time for a given Salmonella strain. Different uppercase letters on the bars indicate significant differences $(p<0.05)$ of bacterial count among days of storage for a given Salmonella strain.

Phage-resistant development in Salmonella was investigated after a treatment with our phage cocktail preparation. A phage cocktail and individual phages included in phage cocktail preparation were re-tested on sub-cultured $S$. Enteritidis and $S$. Typhimurium recovered from a previous phage challenge study. Sub-cultured Salmonella strains previously treated with a phage cocktail presented similar results as the sub-cultured $S$. Enteritidis and $S$. Typhimurium from the non-phage treatment (Table 7). However, individual phages showed similar lysis ability on the sub-cultured Salmonella strains from both the previous treatment and the non-phage treatment. 
Table 7. Lysis ability of a phage cocktail and individual phages included in a phage cocktail preparation on S. Enteritidis (SE) and S. Typhimurium (ST) after being treated with a phage cocktail.

\begin{tabular}{|c|c|c|c|c|c|c|c|c|}
\hline \multirow{4}{*}{ Treatment } & \multicolumn{8}{|c|}{ Lysis Ability $^{a}$} \\
\hline & \multicolumn{2}{|c|}{ Cocktail } & \multicolumn{2}{|c|}{ KP4 } & \multicolumn{2}{|c|}{ KP5 } & \multicolumn{2}{|r|}{ KP50 } \\
\hline & \multicolumn{8}{|c|}{ Phage Titer (PFU/mL) } \\
\hline & $10^{7}$ & $10^{6}$ & $10^{7}$ & $10^{6}$ & $10^{7}$ & $10^{6}$ & $10^{7}$ & $10^{6}$ \\
\hline Control SE (non-phage treatment) & ++ & ++ & ++ & ++ & ++ & ++ & ++ & + \\
\hline Control ST (non-phage treatment) & ++ & + & ++ & + & ++ & - & + & - \\
\hline Phage-treated SE & ++ & ++ & ++ & - & ++ & - & ++ & - \\
\hline Phage-treated ST & ++ & + & ++ & + & ++ & - & + & - \\
\hline
\end{tabular}

a Clear zone or visible plaques were observed as +++ , confluent lysis (clear spot); ++ , semi-confluent lysis (semi-clear); + , turbidity without plaque formation.

\section{Discussion}

The recovery of high number of Salmonella phages in this study suggests that animal farm environments in Songkhla province, Thailand represent an important source of abundant Salmonella phages. Typically, Salmonella phages have been isolated from diverse animal farms such as poultry farms [25,27], swine farms [28,29], goat farms [30] and bovine farms [4,31]. Our study also suggests that free range farms could yield many phages, especially from soil and feed samples. Similar to previously reported sources of phages, Wongsuntornpoj et al. [31] isolated a number of Salmonella phages from small-scale free range cattle farms in Thailand [31]. As the presence of bacteriophage is normally related to bacterial host population [32], samples from free range farms including soil in an open land may have high opportunity to be exposed to various important sources of Salmonella such as wild birds, insects, rodent droppings and other carriers [33].

Variations in the genome size of Salmonella phages obtained in this study indicate the potential diverse phage groups that may be distributed in farm environments in Thailand. Some identical genome sizes were observed among phages from various farms in different countries (Table 8), suggesting presence of common phage types from these animal farm-related sources. Among Salmonella phages isolated from dairy farms in USA, the genome sizes ranging from $22 \mathrm{~kb}$ to $156 \mathrm{~kb}$ [4], while some phages from dairy farms in Thailand exhibited the genome sizes of $40 \mathrm{~kb}$ to $200 \mathrm{~kb}$ [31]. Lysis profiles indicated that our isolated phages showed better ability to lyse Salmonella strains from animal farms in Thailand as compared to strains from USA. Our findings indicate the relationship between phages and Salmonella hosts is due to geological isolation. This phenomenon can be explained by the mechanisms of the phage-host receptors which are related to the evolution as pray-predator [34]. However, the spectrum of phage lysis can be extended across different sources or regions of host habitats. In this study, our isolated phages showed lysis on Salmonella strains from diverse sources including environments related to animal farms, animal slaughterhouses, food processing plants and from humans. Phages could also lyse bacterial hosts from different continents. Overall, phages isolated from animal farms in this study could lyse most serovars of Salmonella that have been reported as the predominant and prevalent serovars in humans, foods and animal farms in Thailand including Salmonella serovars Agona, Anatun, Give, Enteritidis, Kedougou, Kentucky, Typhimurium and Weltevreden $[11,21,35,36]$. Findings here suggests a potential for phage applications against bacterial hosts from various environments in different food chains or countries. 
Table 8. Estimated genome size of Salmonella phages isolated from animal farms in this study and Salmonella phage isolated from previous studies.

\begin{tabular}{llll}
\hline \multicolumn{1}{c}{ Source of Isolation } & Country & Estimated Genome Size (kb) & Reference \\
\hline Goat feces & Thailand & $200 \pm 2$ & This study \\
Bovine feces & Thailand & $50 \pm 2,60 \pm 2$ & This study \\
Poultry feed & Thailand & $60 \pm 2,72 \pm 2$ & This study \\
Soil (poultry farm) & Thailand & $50 \pm 2,60 \pm 2,105 \pm 2$ & This study \\
Drinking water (poultry farm) & Thailand & $97 \pm 2$ & This study \\
Poultry feces & Thailand & $50 \pm 2,60 \pm 2,103 \pm 2$ & This study \\
Dairy farms & USA & 22 to 156 & {$[4]$} \\
Dairy farms & Thailand & 40 to 200 & {$[31]$} \\
Sewage effluent & UK & $40,48.5$ and 155 & {$[37]$} \\
Chicken feces & Korea & 240 & {$[38]$} \\
Sewage (poultry farm) & Korea & 40 & {$[39]$} \\
Water buffalo feces & Southern Italy & 39 & {$[40]$} \\
Swine lagoon effluent (poultry farm) & UK & 42 & {$[41]$} \\
\hline
\end{tabular}

Phage latent period and burst size are major parameters which play an important role in the host lysis system [42]. Phages which present a short latent period and large burst size will be replicated more quickly and the new phage particles (progeny) could be released more efficiently [25]. Our phages combined in a phage cocktail showed a short latent period and large burst size of up to 97.7 and 173.7 PFU/cell on both S. Enteritidis and S. Typhimurium, respectively. The range of Salmonella phage latent periods has been reported within the range of 15 to $45 \mathrm{~min}$ [43]. Abedon et al. [44] reported that shorter phage latent periods could be obtained by higher bacterial densities. It is also suggested that phage exhibiting very short latent periods maybe viewed as specialists for propagation when bacteria within cultures are highly prevalent [44]. Phage burst size has been reported with large variations (5 to $250 \mathrm{PFU} /$ cell) depending on the bacterial strain infected [45]. Overall, the short latent period and large burst size of our phages suggests a rapid replication and effective release of new phage particles from both $S$. Enteritidis and $S$. Typhimurium hosts, thus appropriate for using to control bacterial hosts as reported by previous other studies [46,47].

Our developed phage cocktail showed high efficiency to control $S$. Enteritidis and $S$. Typhimurium in both in vitro study and different food categories that are typically linked to Salmonella and foodborne outbreaks. Our phage cocktail could decrease $S$. Enteritidis on chicken meat and sunflower sprouts by $0.66 \log \mathrm{CFU} / \mathrm{cm}^{2}$ and $1.27 \log \mathrm{CFU} / \mathrm{g}$, respectively. S. Typhimurium on chicken meat and sunflower sprouts were decreased by $1.73 \log \mathrm{CFU} / \mathrm{cm}^{2}$ and $1.17 \log \mathrm{CFU} / \mathrm{g}$, respectively. In a previous study, Grant et al. [48] demonstrated a $<1 \log$ reduction of Salmonella on ground chicken after treatment with the commercial Salmonella phage cocktail (Salmonelex ${ }^{\mathrm{TM}}$, Micreos Food Safety, Wageningen, The Netherlands) [48]. Another phage cocktail showed a reduction of $S$. Enteritidis and S. Typhimurium on chicken breast at 0.9 and $2.2 \log \mathrm{CFU} / \mathrm{g}$, respectively within 7 days at $4{ }^{\circ} \mathrm{C}$ [20]. Our finding showed no evidence of phage resistance in both Salmonella serovars upon phage cocktail treatment. This phenomenon might be related to the biology (latent period and burst size) of the phages included in our phage cocktail. Short periods of time to kill bacterial hosts for phages is an important factor that prevents the occurrence of bacteria resistance to phage [43].

\section{Conclusions}

This study aims to understand the abundance and diversity of Salmonella phages in animal farm environments. Phages presenting an ability to lyse Salmonella strains from different sources in the food chain and countries were included for development of Salmonella phage cocktail. Phages from our collection obtained from animal farms in Thailand indicate diverse and effective phages that can be used as a biocontrol agent to control $S$. Enteritidis and $S$. Typhimurium in different food categories. In addition, phage lysis profiles indicated that our isolated phages showed a high ability to lyse several important serovars of Salmonella predominant in various sources and prevalent in different countries. 
Phages composed in our developed cocktail showed a rapid replication and effective release of new phage particles from both $S$. Enteritidis and $S$. Typhimurium hosts as indicated by short latent period and large burst size. The developed phage cocktail in this study showed to be highly effective for the reduction of $S$. Enteritidis and $S$. Typhimurium in fresh foods, especially those that have been highly related to Salmonella contamination and foodborne outbreaks.

Author Contributions: K.P., S.B., S.C., A.I.M.S., and K.V. designed the experiments. K.P. performed the experiments and performed statistical analyses. K.P. and K.V. analysed data and wrote the manuscript.

Funding: Prince of Songkla University (AGR570552S to K.V). Supports from the TRF Distinguished Research Professor Grant (to S.B.) and the Ph. D scholarship from Graduate School of Prince of Songkla University (to K.P.)

Acknowledgments: This project is funded by Prince of Songkla University (AGR570552S to K.V.). Supports from the TRF Distinguished Research Professor Grant (to S.B.) and the Ph. D scholarship from Graduate School of Prince of Songkla University (to K.P.) are also acknowledged.

Conflicts of Interest: The authors declare no conflict of interest.

\section{References}

1. García, V.; Mandomando, I.; Ruiz, J.; Herrera-León, S.; Alonso, P.L.; Rodicio, M.R. Salmonella enterica serovars Typhimurium and Enteritidis causing mixed infections in febrile children in Mozambique. Infect. Drug Resist. 2018, 11, 195-204. [CrossRef]

2. Center for Disease Control and Prevention. Salmonella. Available online: https://www.cdc.gov/salmonella/ index.html (accessed on 23 October 2018).

3. Cummings, K.J.; Warnick, L.D.; Alexander, K.A.; Cripps, C.J.; Gröhn, Y.T.; James, K.L.; McDonough, P.L.; Reed, K.E. The duration of fecal Salmonella shedding following clinical disease among dairy cattle in the northeastern USA. Prev. Vet. Med. 2009, 92, 134-139. [CrossRef] [PubMed]

4. Moreno Switt, A.I.; den Bakker, H.C.; Vongkamjan, K.; Hoelzer, K.; Warnick, L.D.; Cummings, K.J.; Wiedmann, M. Salmonella bacteriophage diversity reflects host diversity on dairy farms. Food Microbiol. 2013, 36, 275-285.

5. Shahzad, A.; Mahmood, M.Sh.; Hussain, I.; Siddique, F.; Abbas, R.Z. Prevalence of Salmonella species in hen eggs and egg storing-trays collected from poultry farms and marketing outlets of Faisalabad, Pakistan. Pak. J. Agric. Sci. 2012, 49, 565-568.

6. United States Department of Agriculture. Serotypes Profile of Salmonella Isolates from Meat and Poultry Products January 1998 through December 2014. Available online: https:/ / www.fsis.usda.gov/wps/wcm/ connect/3866026a-582d-4f0e-a8ce-851b39c7390f/Salmonella-Serotype-Annual-2014.pdf?MOD=AJPERES (accessed on 23 October 2018).

7. Reddy, S.P.; Wang, H.; Adams, J.K.; Feng, P.C.H. Prevalence and characteristics of Salmonella serotypes isolated from fresh produce marketed in the United States. J. Food Prot. 2016, 79, 6-16. [CrossRef]

8. Ponce, E.; Khan, A.; Cheng, C.M.; Summage-West, C.; Cerniglia, C.E. Prevalence and characterization of Salmonella enterica serovar Weltevreden from imported seafood. Food Microbiol. 2008, 25, 29-35. [CrossRef]

9. Shabarinath, S.; Sanath Kumar, H.; Khushiramani, R.; Karunasagar, I.; Karunasagar, I. Detection and characterization of Salmonella associated with tropical seafood. Int. J. Food Microbiol. 2007, 114, 227-233. [CrossRef]

10. Espigares, E.; Bueno, A.; Espigares, M.; Gálvez, R. Isolation of Salmonella serotypes in wastewater and effluent: Effect of treatment and potential risk. Int. J. Hyg. Environ. Health 2006, 209, 103-107. [CrossRef] [PubMed]

11. Bangtrakulnonth, A.; Pornreongwong, S.; Pulsrikarn, Ch.; Sawanpanyalert, P.; Hendriksen, S.R.; Wong, D.; Arestrupt, F.M. Salmonella serovars from humans and other sources in Thailand 1993-2003. Emerg. Infect. Dis. 2004, 10, 131-135.

12. Center for Disease Control and Prevention. Reports of Salmonella Outbreak Investigations from 2018. Available online: https:/ / www.cdc.gov/salmonella/outbreaks-2018.html (accessed on 23 October 2018).

13. Hanning, I.B.; Nutt, J.D.; Ricke, S.C. Salmonellosis outbreaks in the United States due to fresh produce: Sources and potential intervention measures. Food Pathog. Dis. 2009, 6, 635-648. [CrossRef]

14. Clokie, M.R.; Millard, A.D.; Letarov, A.V.; Heaphy, S. Phages in nature. Bacteriophage 2011, 1, 31-45. [CrossRef] 
15. Díaz-Muñoz, S.L.; Koskella, B. Bacteria-phage interactions in natural environments. Adv. Appl. Microbiol. 2014, 89, 135-183.

16. Kazi, M.; Annapure, U.S. Bacteriophage biocontrol of foodborne pathogens. J. Food Sci. Tech. 2016, 53, 1355-1362. [CrossRef]

17. Fister, S.; Robben, C.; Witte, A.K.; Schoder, D.; Wagner, M.; Rossmanith, P. Influence of environmental factors on phage-bacteria interaction and on the efficacy and infectivity of phage P100. Front. Microbiol. 2016, 7, 1-13. [CrossRef]

18. Thung, T.T.; Premarathne, K.; Chang, W.S.; Loo, Y.Y.; Chin, Y. Zh.; Kuan, Ch.H.; Tan, Ch.W.; Basri, D.F.; Jasimah, Ch.W.; Radu, S. Use of a lytic bacteriophage to control Salmonella Enteritidis in retail food. LWT-Food Sci. Technol. 2017, 78, 222-225. [CrossRef]

19. Kocharunchitt, C.; Ross, T.; McNeil, D.L. Use of bacteriophages as biocontrol agents to control Salmonella associated with seed sprouts. Int. J. Food. Microbiol. 2009, 128, 453-459. [CrossRef]

20. Spricigo, D.A.; Bardina, C.; Cortés, P.; Llagostera, M. Use of a bacteriophage cocktail to control Salmonella in food and the food industry. Int. J. Food Microbiol. 2013, 165, 169-174. [CrossRef]

21. Padungtod, P.; Kaneene, J.B. Salmonella in food animals and humans in northern Thailand. Int. J. Food Microbiol. 2006, 108, 346-354. [CrossRef]

22. Vongkamjan, K.; Moreno Switt, A.I.; Den, H.C.; Fortes, E.D.; Wiedmann, M. Silage collected from dairy farms harbors an abundance of Listeria phages with considerable host range and genome size. Appl. Environ. Microbiol. 2012, 78, 8666-8675. [CrossRef] [PubMed]

23. R Development Core Team. R: A Language and Environment for Statistical Computing. Available online: http:/ / www.R.-project.org/ (accessed on 20 January 2019).

24. Mirzaei, M.K.; Nilsson, A.S. Correction: isolation of phages for phage therapy: A comparison of spot tests and efficiency of plating analyses for determination of host range and efficacy. PLoS ONE 2015, 10, e0127606. [CrossRef]

25. Bao, H.; Zhang, H.; Wang, R. Isolation and characterization of bacteriophages of Salmonella enterica serovar Pullorum. Poult. Sci. 2011, 90, 2370-2377. [CrossRef] [PubMed]

26. Food and Agriculture Organization of the United Nations and World Health Organization. Joint FAO/WHO Food Standards Programme Codex Committee on Fish and Fishery Products, Discussion Paper on the Use of Chlorinated Water. 2000. CX/FFP 00/13. Available online: http:/ / www.fao.org/tempref/codex/Meetings/ CCCF/CCCF5/cf05_INF.pdf (accessed on 23 October 2018).

27. Hungaro, M.H.; Santos Mendonca, R.C.; Gouvea, D.M.; Danatas Vanetti, M.C.; de Oliveira Pinto, C.L. Use of bacteriophages to reduce Salmonella in chicken skin in comparison with chemical agents. Food Res. Int. 2013, 52, 75-81. [CrossRef]

28. Callaway, T.R.; Edrington, T.S.; Brabban, A.; Kutter, E.; Karriker, L.; Stahl, C.; Wagstrom, E.; Anderson, R.C.; Genovese, K.; McReynolds, J.; et al. Occurrence of Salmonella-specific bacteriophages in swine feces collected from commercial farms. Foodborne Pathog. Dis. 2010, 7, 851e856. [CrossRef] [PubMed]

29. McLaughlin, M.R.; Balaa, M.F.; Sims, J.; King, R. Isolation of Salmonella bacteriophages from swine effluent lagoons. J. Environ. Qual. 2006, 35, 522-528. [CrossRef] [PubMed]

30. Shukla, K.S.; Hirpurkar, S.D.; Singh, S.K.; Rajoria, R. Isolation of phage from animal waste of different LSF and their utility in phage therapy. Int. J. Curr. Microbiol. Appl. Sci. 2014, 3, 205-210.

31. Wongsuntornpoj, S.; Moreno Switt, A.I.; Bergholz, P.; Wiedmann, M.; Chaturongakul, S. Salmonella phages isolated from dairy farms in Thailand show wider host range than a comparable set of phages isolated from U.S. dairy farms. Vet. Microbiol. 2014, 172, 345-352. [CrossRef] [PubMed]

32. Chibani-Chennoufi, S.; Bruttin, A.; Dillmann, M.L.; Brússow, H. Phage-host interaction: An ecological perspective. J. Bacteriol. 2004, 186, 3677-3686. [CrossRef]

33. Bailey, J.S.; Cosby, D.E. Salmonella prevalence in free-range and certified organic chickens. J. Food Prot. 2005, 68, 245-2453. [CrossRef]

34. Chaturongakul, S.; Ounjai, P. Phage-host interplay: Examples from tailed phages and Gram-negative bacterial pathogens. Front. Microbiol. 2014, 5, 442. [CrossRef] [PubMed]

35. Saengthongpinit, C.; Nane-Siri, D.; Aparachita, P.; Apiwannarat, P.; Buakhao, P.; Bowornnantiwath, W.; Thengchaisri, N.; Songserm, T. Longitudinal study of Salmonella and Campylobacter species from two laying duckling flocks in the central region of Thailand. Thai J. Vet. Med. 2014, 44, 355-361. 
36. Vaeteewootacharn, K.; Sutra, S.; Vaeteewootacharn, S.; Sithigon, D.; Jamjane, O.; Chomvarin, C.; Hahnvajanawong, C.; Thongskulpanich, N.; Thaewnon-giew, K. Salmonellosis and the food chain in Khon Kaen, northeastern Thailand. Southeast Asian J. Trop. Med. Public Health 2005, 36, 123-129.

37. Hooton, S.P.; Atterbury, R.J.; Connerton, I.F. Application of a bacteriophage cocktail to reduce Salmonella Typhimurium U288 contamination on pig skin. Int. J. Food Microbiol. 2011, 151, 157-163. [CrossRef]

38. Lee, J.H.; Shin, H.; Kim, H.; Ryu, S. Complete genome sequence of Salmonella bacteriophage SPN3US. J. Virol. 2011, 85, 13470-13471. [CrossRef]

39. Kim, S.H.; Park, J.H.; Lee, B.K.; Kwon, H.J.; Shin, J.H.; Kim, J.; Kim, S. Complete genome sequence of Salmonella bacteriophage SS3e. J. Virol. 2012, 86, 10253-10254. [CrossRef]

40. Paradiso, R.; Orsini, M.; Bolletti Censi, S.; Borriello, G.; Galiero, G. Complete genome sequence of a Myoviridae bacteriophage infecting Salmonella enterica serovar Typhimurium. Genome Announc. 2016, 4, e00940-16. [CrossRef]

41. Turner, D.; Hezwani, M.; Nelson, S.; Salisbury, V.; Reynolds, D. Characterization of the Salmonella bacteriophage vB_SenS-Ent1. J. Gen. Virol. 2012, 93, 2046-2056. [CrossRef]

42. Santos, S.B.; Carvalho, C.; Azeredo, J.; Ferreira, E.C. Population dynamics of a Salmonella lytic phage and its host: Implications of the host bacterial growth rate in modelling. PLoS ONE 2014, 9, e102507. [CrossRef]

43. Calsina, A.; Palmada, J.-M.; Ripoll, J. Optimal latent period in a bacteriophage population model structured by infection-age. Math. Models Methods Appl. Sci. 2011, 21, 1-26. [CrossRef]

44. Abedon, S.T.; Hyman, P.; Thomas, C. Experimental examination of bacteriophage latent-period evolution as a response to bacterial availability. Appl. Environ. Microbiol. 2003, 69, 7499-7506. [CrossRef]

45. Wommack, E.K.; Colwell, R.R. Virioplankton: Viruses in aquatic ecosystems. Microbiol. Mol. Biol. Rev. 2000, 64, 69-114. [CrossRef]

46. Cao, F.; Wang, X.; Wang, L.; Li, Z.; Che, J.; Wang, L.; Li, X.; Cao, Z.; Zhang, J.; Jin, L.; Xu, Y. Evaluation of the efficacy of a bacteriophage in the treatment of Pneumonia induced by multidrug resistance Klebsiella Pneumoniae in mice. BioMed Res. Int. 2015, 2015, 752930.

47. Kalatzis, P.G.; Bastías, R.; Kokkari, C.; Katharios, P. Isolation and characterization of two lytic bacteriophages, $\varphi \mathrm{St} 2$ and $\varphi \mathrm{Grn} 1$; phage therapy application for biological control of Vibrio alginolyticus in aquaculture live feeds. PLoS ONE 2016, 11, e0151101. [CrossRef] [PubMed]

48. Grant, A.; Salina, P.; Jurgen, S.; Fawzy, H.; Bob, V. Reduction of Salmonella in ground chicken using a bacteriophage. Poult. Sci. 2017, 96, 2845-2852. [CrossRef] [PubMed] 